\title{
ЗАДАЧА ЕФЕКТИВНОГО УПРАВЛІННЯ ПРОЦЕСОМ ОТРИМАННЯ ТОНКОДИСПЕРСНОГО ПОРОШКУ ДІОКСИДУ ТИТАНУ В ХОДІ ВИХРОВОЇ СУШКИ
}

\author{
Марчевський В.М., Гробовенко Я.В. \\ Національний технічний університет України «Київський політехнічний інститут імені Ігоря Сікорського», Київ, \\ Україна \\ ORCID: 0000-0001-6530-0467ํㅗㄴ 0000-0002-0618-4379² \\ E-mail: v.m.marchecsky@gmail.com ${ }^{1}$,ygrobovenko@gmail.com² \\ Copyright (C) 2018 by author and the journal "Automation technologies and business - processes. \\ This work is licensed under the Creative Commons Attribution International License (CC BY). \\ http://creativecommons.org/licanses/by/4.0
}

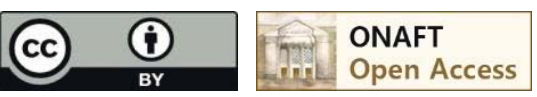

\section{DOI: $10.15673 /$ atbp.v10i1.874}

\begin{abstract}
Анотація: авторами статті обтрунтовано фізичну модель процесу сушіння пасти діоксиду титану та досушування тонкодисперсного порошку $\mathrm{TiO}_{2}$ до залишкової вологості 0,3\%, на основі якої розвинена математична модель процесу сушіння. Результатом розв'язку математичної моделі є кінетичні параметри процесу сушіння, за допомогою яких було розроблено, спроектовано $i$ виготовлено оригінальний сушильний апарат вихрового типу. Результати моделювання були перевірені шляхом експериментальних досліджень процесів сушіння $і$ досушування пасти $\mathrm{TiO}_{2}$ та отримані дослідні графічні залежності зміни швидкості сушіння та температури продукту від часу сушіння. Проаналізовано отримані залежності $і$ встановлені необхідні початкові параметри теплоносія, щзо дозволяють збільиити швидкість сушіння та зменшити енергозатрати на проведення процесу сушіння.

Реалізовано процес сушіння пасти діоксиду титану у вихровому потоці теплоносія при застосуванні оригінальної конструкиї сушильного апарату із диспергатором та зоною досушування матеріалу до високої залишкової сухості 99,7\%. Забезпечено інтенсивне подрібнення конгломератів матеріалу та їх перемішування із вже підсушеним тонкодисперсним продуктом. Наявність зони сепарування частинок вже підсушеного порошку від конгломератів пасти забезпечує ефективне подрібнення останніх та збільшення поверхні контакту вологого матеріалу із теплоносієм. Питоме навантаження поверхні шару конгломератів пасти $\mathrm{TiO}_{2}$ у вихровому потоці за вологою має

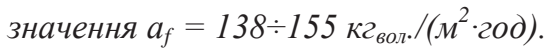

Отриманий, в результаті дослідів, тонкодисперсний порошок діоксиду титану відповідає вимогам державних стандартів та володіє необхідними механічними і споживчими властивостями.

Abstract: The authors of the article justified the physical model of the drying process of titanium dioxide paste and the drying of $\mathrm{TiO}_{2}$ fine powder to a residual moisture content of $0.3 \%$, on the basis of which a mathematical model of the drying process is developed. The result of solving the mathematical model is the kinetic parameters of the drying process, with the help of which the original drying apparatus of the vortex type was designed, designed and manufactured. The results of the simulation were verified by experimental studies of the drying and drying of $\mathrm{TiO}_{2}$ paste, and experimental graphical dependences of the drying rate and product temperature on the drying time were obtained. The obtained dependences are analyzed and the necessary initial parameters of the coolant are established, which allow increasing the drying rate and reducing energy costs for the drying process.

The process of drying the titanium dioxide paste in the vortex flow of the heat carrier during the application of the original design of the drying apparatus with the dispersant and the zone of drying of the material to a high residual dryness of 99.7\% is implemented. Ensuring intensive grinding of conglomerates of the material and mixing them with an already dried, finegrained product. The presence of separation zone of particles of already dried powder from conglomerates of the paste provides effective grinding of the latter and an increase in the contact surface of the wet material with the coolant. Specific load of the surface of the layer of conglomerates of the paste $\mathrm{TiO}_{2}$ in the vortex flow for moisture has the value $a_{f}=138 \div 155$ $\mathrm{kg}_{\mathrm{w}} \mathrm{d}\left(\mathrm{m}^{2} \cdot \mathrm{h}\right)$.
\end{abstract}

As a result of the experiments, the fine powder of titanium dioxide fits the requirements of state standards and possesses the necessary mechanical and consumer properties.

Ключові слова: сушіння, моделювання, теплоносій, діоксид титану, сушильний апарат, вологовміст, кінетика.

Keywords: drying, modeling, coolant, titanium dioxide, drying apparatus, moisture content, kinetics. 
Постановка проблеми. Процес сушіння пасти діоксиду титану є найбільш енергоємний і лімітуючий процес в технології виробництва $\mathrm{TiO}_{2}$, який вимагає зменшення витрат теплової енергії на сушіння пасти даного продукту, збільшення швидкості сушіння та підвищення якості і забезпечення низької залишкової вологості готового продукту. Тому дослідження процесу сушіння пасти діоксиду титану та розробка нового високоефективного і енергоощадного обладнання для отримання продукту $\mathrm{TiO}_{2}$ iз високими заданими механічними і споживчими властивостями $\epsilon$ актуальною задачею.

Аналіз останніх досліджень і публікацій. Теоретичним моделюванням тепломасообмінних процесів у сушильних апаратах з киплячим шаром займалися C-G. A. Berg [1] та D. E. Oakley [2]. Вплив гідродинаміки вихрових потоків у двохфазних системах на геометрію тепломасообмінного обладнання розглядався в роботах $[4,5]$.

Аналіз фізичної моделі і рішень математичного описання процесу сушіння тонкодисперсних паст, виконаний нами в роботі [6], Малаховим М.М. в роботі [7] та Алексаняном І.Ю. в роботі [9], показав, що на процес сушіння пасти має істотний вплив швидкісній режими вихрових потоків теплоносія, час перебування продукту в сушильній камері, початкові параметри теплоносія та ступінь подрібнення агломератів продукту.

Однак в перелічених роботах моделювання процесу сушіння і досушування діоксиду титану, визначення коефіцієнту сушіння та швидкостей сушіння $\mathrm{TiO}_{2}$ не розглядалося, тому звідси і випливає мета даної роботи.

Мета дослідження. Провести теоретичне моделювання процесів сушіння та досушування пасти діоксиду титану, отримати основні кінетичні параметри, які експериментально підтвердити на оригінальному сушильному вихровому апараті.

Викладення основного матеріалу. В сучасних умовах в технологіях ефективного управління процесами отримання дрібнодисперсного порошку діоксиду титану $\mathrm{TiO}_{2}$ лімітуючим та найбільш енергоємним процесом є сушіння пасти. Важливо, щоб залишкова сухість порошку діоксиду титану складала не менше 99,7 \%. На досягнення такої величини сухості необхідно затратити значну енергії, а також застосовувати відповідний сушильний апарат, будова і принцип дії якої забезпечити необхідне подрібнення частинок пасти до утворення дрібнодисперсного порошку, а також його досушування до високої кінцевої сухості і сепарування від сушильного агенту. Важливо, щоб разом із процесом сушіння відбувався інтенсивний процес подрібнення гранул матеріалу до отримання дрібнодисперсного порошку.

Процес сушіння тонкодисперсної пасти діоксиду титану, як об'єкт управління має дві основні стадії. На першій стадії відбувається диспергування пасти 3 додаванням підсушеного порошку і висушування поверхневої вологи. На другій стадії відбувається досушування дрібнодисперсного порошку в потоці теплоносія до кінцевої залишкової сухості 99,7\%.

Представлений спосіб сушіння можна здійснити в оригінальній сушильній установці, схема якої показана на рисунку 16.

Ефективне управління роботою сушильного апарату залежить від повного контролю над технологічними параметрами теплоносія та продукту діоксиду титану. Це реалізується безперервним отриманням значень вологовмістів та температур порошку $\mathrm{TiO}_{2}$ i теплоносія за допомогою датчиків 8 та візуалізацією даних на дисплеї комп'ютера 10 з використанням мікроконтролера Arduino Pro Mini 9.

Сушильний агент, в кількості Q, ${ }^{3}$ /с, подається через патрубок 1 в дифузор 2, який розподіляє потоки теплоносія $\mathrm{i}$ направляє їх в диспергатор 3, де потоки закручуються у вихровий потік за напрямком обертання ножів. Одночасно у верхню частину сушильної камери (рисунок 2) тангенційно вводиться, через патрубок 8, сушильний агент кількістю $\mathrm{kQ}, \mathrm{m}^{3} / \mathrm{c}$, на досушування тонкодисперсних частинок матеріалу. Вологий матеріал подається в середину сушильної камери 4 за допомогою системи подачі 7. В результаті два потоки зустрічаються в сушильній камері і утворюється загальний закручений вихровий потік сушильного агенту і частинок вологого матеріалу.

Вихровий потік теплоносія відіграє важливу роль в проведенні тепломасообмінних процесів між двома фазами системи; винесенні із зони диспергування кондиційного матеріалу і направлення його в зону досушування; опудренні поверхні агломератів вологого матеріалу вже висушеним порошком; транспортуванні тонких дисперсій між зонами А і В сушильного апарату.

В першій зоні А відбувається диспергування тонкодисперсного матеріалу із додаванням підсушеного порошку і висушування поверхневої вологи. В другій пристінній зоні В відбувається розділення твердої фракції за рахунок відцентрової сили, що відкидає важкі частинки на конусоподібну поверхню сушильної камери, які переміщуються знову в зону диспергування А. Далі вже підсушений тонкодисперсний матеріал переміщається в зону досушування С, після чого потрапляє в зону сепарації D. 

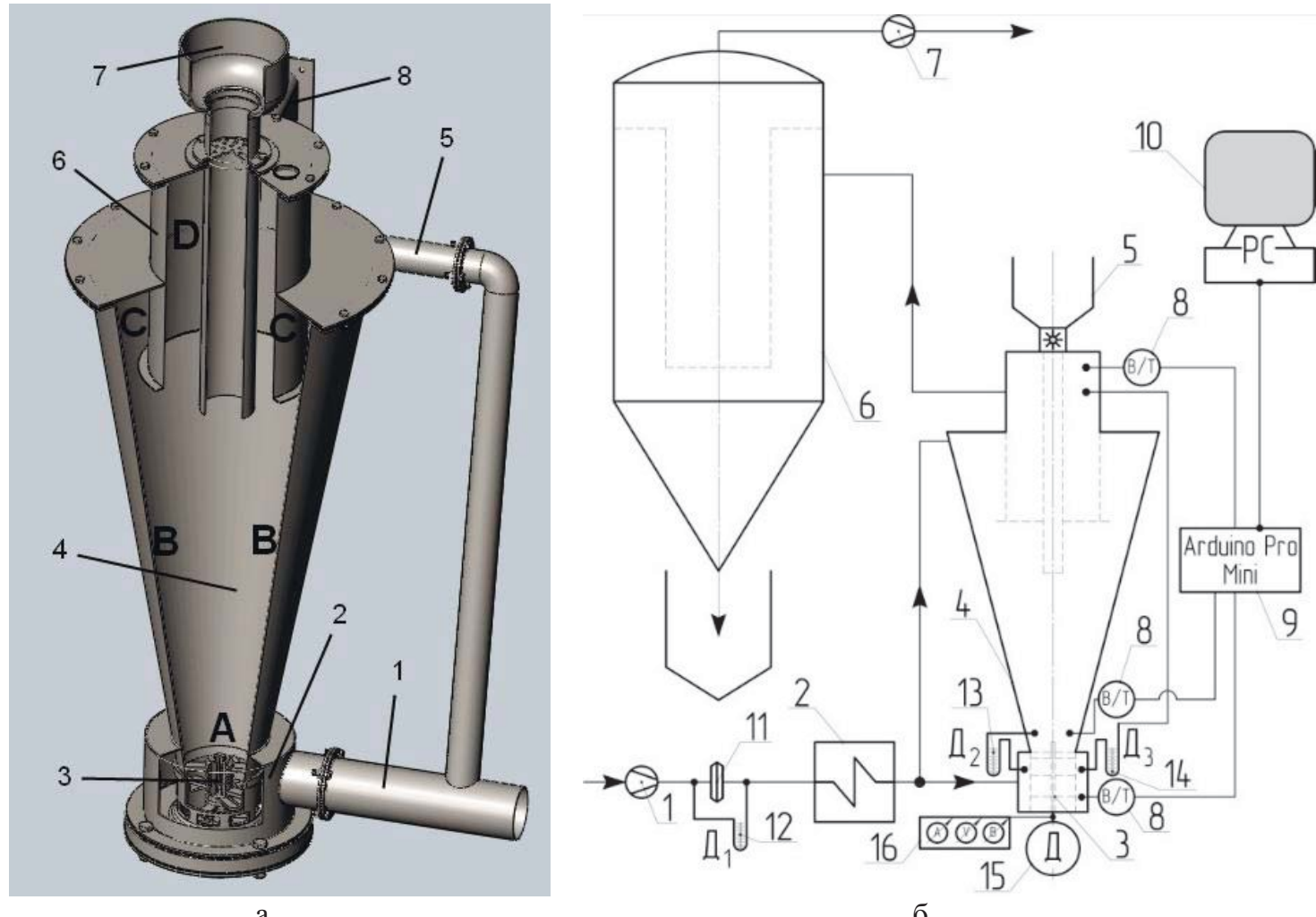

б

a- оригінальний сушильний апарат вихрового типу: $\boldsymbol{A}$ - зона диспергування; $\boldsymbol{B}$ - зона розділення фракцій;

$\boldsymbol{C}$ - зона інтенсивного досушування; $\boldsymbol{D}$ - зона сепарування; 1 - основний патрубок подачі сушильного агенту;

2 - дифузор; 3 - диспергатор; 4 - конусоподібна сушильна камера; 5 - патрубок подачі сушильного агенту для

досушування; 6 - циліндр сепарації; 7 -система подачі вологих дисперсій; 8 - вихідний патрубок;

б-схема сушильної установки: 1, 7 - нагнітаючий і витяжний вентилятори; 2 - калорифер; 3 - диспергатор; 4 сушильна камера; 5 - живильник-дозатор; 6-рукавний фільтр; 8 - датчик температури і вологості MLX90614; 9 мікроконтролер Arduino Pro Mini; 10 - комп'ютер для візуалізаиії та збереження даних;

11 - діафрагма; 12, 13, 14 - дифманометри; 15 - електропривід; 16 - вимірювальний комплекс типу К50 №1654 $a$-original drying apparatus of the vortex type: A - zone of dispersion; B - fractional separation zone; $C$-zone of intensive drying; D - separation zone; 1 - main delivery nozzle for the drying agent; 2 -diffuser; 3 -dispersant;

4 - cone-shaped drying chamber; 5 - nozzle for supplying the drying agent to drying; 6 - separation cylinder; 7 - system of supply of moist dispersions; 8 - outlet pipe;

$b$ - scheme of the drying plant: 1, 7 - boiling and exhaust fans; 2 - heater; 3 -dispersant; 4 -drying chamber;

5 - feeder-dispenser; 6 - sleeve filter; 8 - temperature and humidity sensor MLX90614; 9 - Microcontroller Arduino Pro Mini; 10 - computer for visualization and data storage; 11 -diaphragm; 12, 13, 14 -difemometers; 15 - electric drive; 16 measuring complex type K50 №1654

\section{Рис. 1 - Схема оригінального сушильного апарату для отримання тонких дисперсій}

Фізична модель процесів сушіння і досушування пасти $\mathrm{TiO}_{2}$ включає (рис. 2):

- подачу тиксотропної пасти діоксиду титану у вигляді сформованих окремих кластерів частинок $\mathrm{TiO}_{2}$, що з'єднані між собою силами поверхневого натягу у зону вихрового шару А;

- контакт і припудрювання поверхні кластерів із вже підсушеним продуктом;

зоні А за допомогою ножового диспергатора;

- $\quad$ винесення дрібних частинок продукту із зони А в сепараційну зону В вихровим потоком теплоносія при зменшенні осьової складової швидкості;

- сепарація і досушування адсорбційно-зв'язаної вологи в зоні С тонкодисперсних частинок до низької залишкової вологості 0,3\%. 


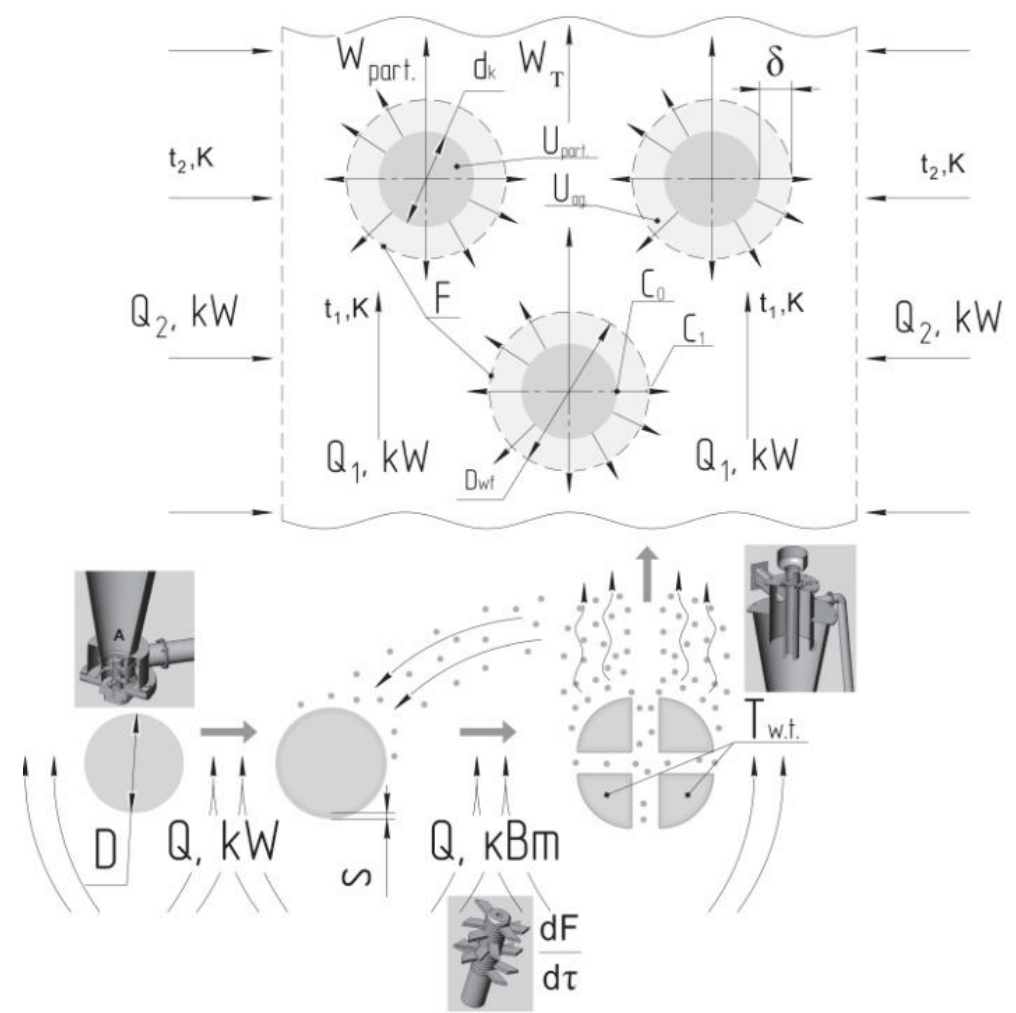

Рис. 2 - Фізична модель сушіння агломератів пасти діоксиду титану

Математична модель процесу сушіння $\mathrm{TiO}_{2}$, складено на основі рівняння теплової енергії, основного рівняння масовіддачі [5] та закону подрібнення [6] можна представити наступною системою рівнянь (1):

$$
\left\{\begin{array}{c}
\frac{\partial t_{\text {част }}}{\partial \tau}=\alpha \cdot \frac{\partial F_{\text {част }}}{\partial \tau} \cdot \frac{t_{\text {с.а. }}-t_{\text {част }}}{G_{\text {aас.п. }} \cdot\left(\mathrm{c}_{\text {а.с.п. }}+c_{\mathrm{B}} \cdot U\right)}-\frac{\frac{\partial U}{\partial \tau} \cdot r}{\text { сас.п. }+c_{\mathrm{B}} \cdot U} \\
\frac{\partial U}{\partial \tau}=\beta \cdot \frac{\partial F_{\text {част }}}{\partial \tau} \cdot \frac{P_{S} \cdot(1-\varphi)}{P_{\text {атм. }}}-D \cdot \sum F_{\text {част }} \cdot \frac{\partial C}{\partial R} \\
\frac{\partial F_{\text {част }}}{\partial \tau}=k Z
\end{array}\right.
$$

де $G_{\text {а.с.п. }}$ - витрати абсолютно сухого порошку діоксиду титану, $\frac{\text { кг }}{\mathrm{c}} w$ - швидкість сушильного агенту (повітря), $\frac{\mathrm{m}}{\mathrm{c}} ;$ - еквівалентний діаметр частинки пасти діоксиду титану, м; $v_{\text {с.а. }}$ - кінематична в 'язкість сушильного агенту, $\frac{\mathrm{m}^{2}}{\mathrm{c}} ; \mathrm{c}_{\text {а.с.п. }}-$

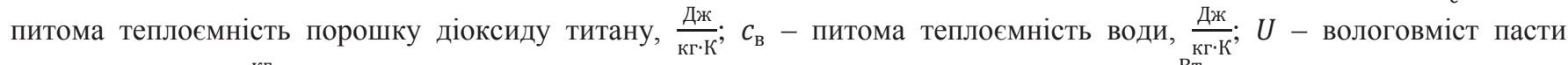
діоксиду титану, $\frac{\kappa_{\text {в }}}{\kappa_{\text {а.с.м }}} ; \alpha-$ коефіцієнт масовіддачі від теплоносія до поверхні частинки, $\frac{\text { Вт }}{\mathrm{m}^{2} \cdot \mathrm{\kappa}^{\prime}} F_{\text {част }}-$ зовнішня поверхня частинки, $\mathrm{m}^{2} ; t_{\text {с.а. }}-$ температура сушильного агенту, ${ }^{\circ} \mathrm{C} ; t_{\text {част }}-$ температура частинки, ${ }^{\circ} \mathrm{C} ; \frac{d U}{d \tau}-$ швидкість сушіння, $\frac{1}{c} ; r-$ питома теплота пароутворення, $\frac{\text { Дж }}{\text { кг }} d \tau$ - час сушіння; $\beta$ - коефіцієнт масовіддачі від теплоносія до поверхні частинки, $\frac{\text { м}}{c} ; P_{S}$ - тиск насиченої пари, Па; $\varphi$ - відносна вологість теплоносія, \%; $D$ - коефіцієнт молекулярної дифузії, м/с; $k$ коефіцієнт подрібнення; z - ступінь подрібнення; дС - рушійна сила процесу досушування.

Початкові умови для даної системи рівнянь (1):

$$
\left.u\right|_{\tau=0}=u_{0}, u_{2}=u_{1 \mathrm{\kappa p},} \tau_{0}=0, t_{0}=t_{1}, d_{0}=1 \mathrm{мм}
$$

Залежність $\frac{\partial F_{\text {част }}}{\partial \tau}$ описує процес диспергування агломератів пасти $\mathrm{TiO}_{2}$, враховуючи швидкість обертання, довжину ріжучих кромок та форму ножів диспергатора.

Математичну модель я процесу сушіння пасти діоксиду титану (1) розв'язано, з урахуванням початкових умов (2), методом Рунге-Кутти. Результати розрахунків наведено на рисунку 3. 

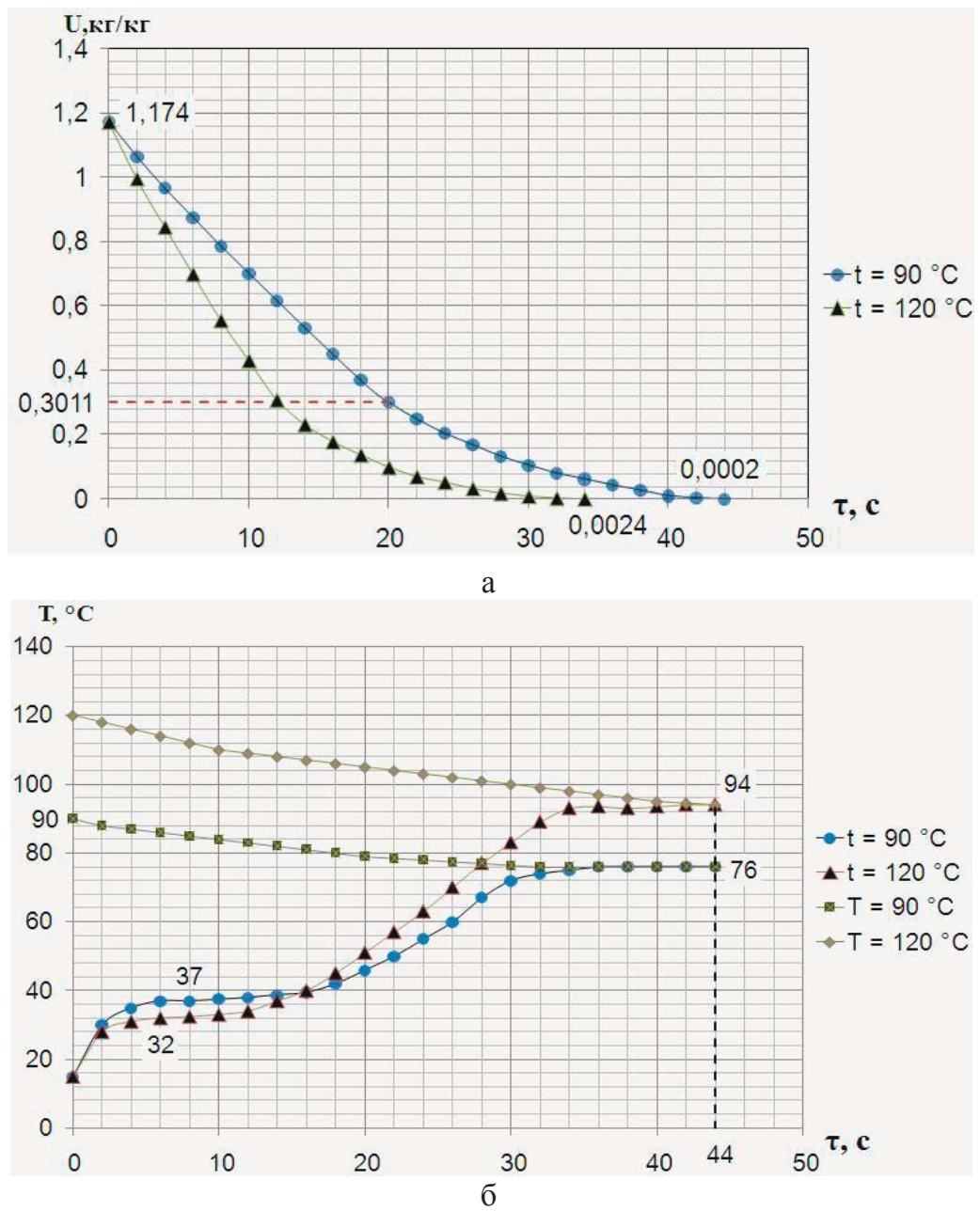

a - залежність вологовмісту $U$ пасти $\mathrm{TiO}_{2}$ від часу сушіння $\tau$; 6 - Залежність температури $t$ продукту від часу сушіння $\tau$

Рис. 3 - Результати розв'язання математичної моделі процесу сушіння пасти діоксиду титану

Залежність вологовмісту від часу показує, що процес сушіння пасти включає період нагрівання до температури

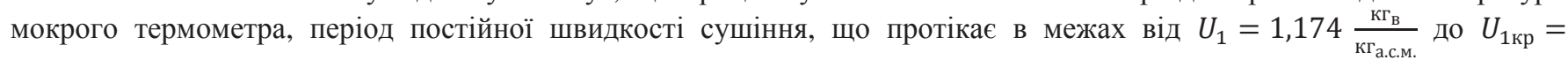

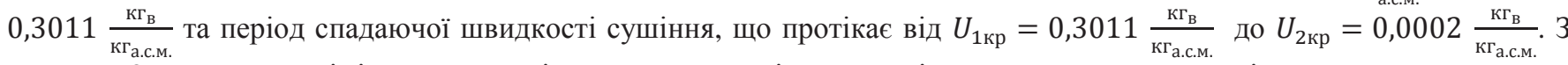
рисунку 3 видно, що лімітуючою стадією процесу сушіння є період спадаючої швидкості, в якому висушується адсорбована волога. Основний процес сушіння пасти починається від значення початкового вологовмісту пасти $U=1,174 \frac{\text { кгв. }}{\text { кга.см. }}$ і завершується значенням $U_{1 к р}$ та характеризується постійною швидкістю сушіння. Процес досушування тонкодисперсних частинок $\mathrm{TiO}_{2}$ до рівноважного вологовмісту $U_{\mathrm{p}}=0,002 \frac{\text { кг }}{\text { кг.с.м. }_{\text {в. }}}$ відбувається в другому періоді сушіння при падаючій швидкості сушіння.

Експериментальні дослідження процесів сушіння та досушування тонкодисперсної пасти діоксиду титану було проведено при об'ємних витратах теплоносія $50 \frac{\mathrm{m}^{3}}{\text { год. }}$ та початкових температурах 90 та $120{ }^{\circ} \mathrm{C}$ і початковій вологості пасти $\mathrm{TiO}_{2} 54 \%$. Порівняння експериментальних та теоретичних результатів значень зміни вологовмісту і температури продукту від часу сушіння представлено на рис. 4,5. 


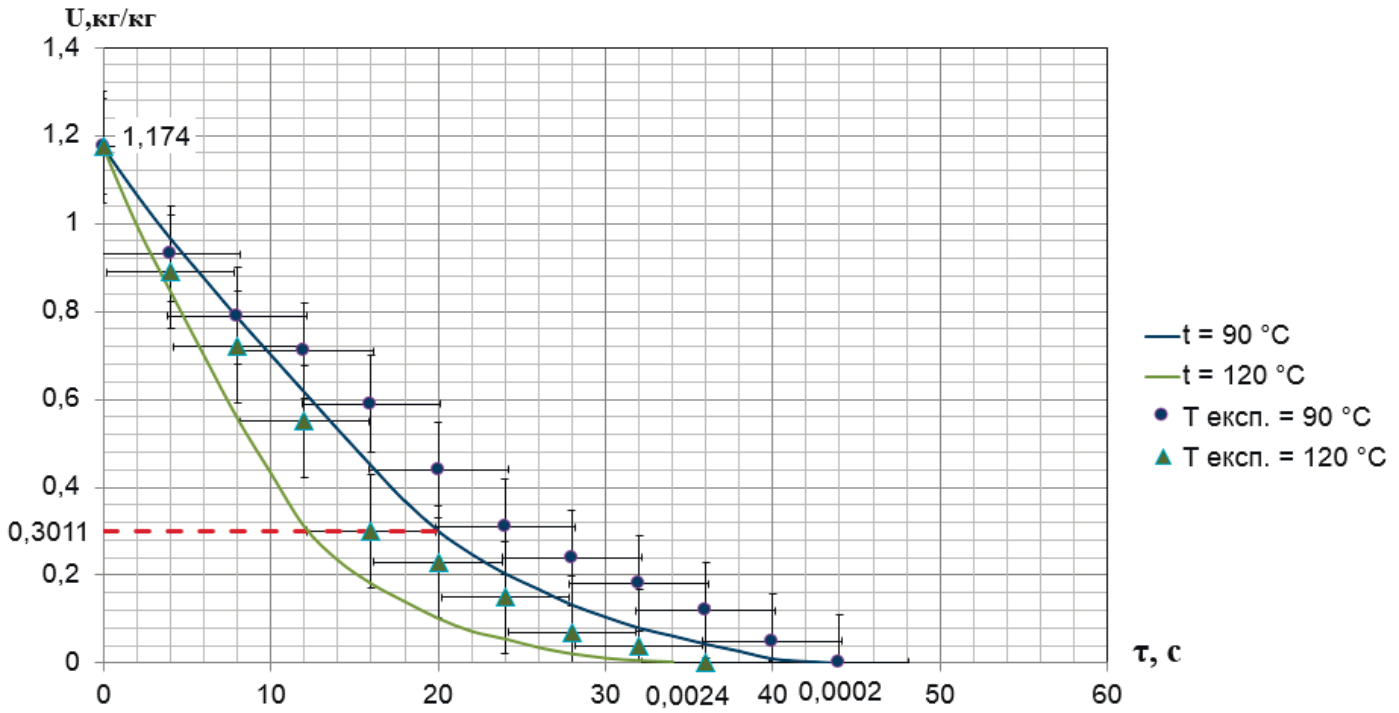

Рис. 4 - Порівняння теоретичних і експериментальних значень вологовмісту пасти діоксиду титану від часу сушіння

Для теоретичних і експериментальних значень вологовмісту продукту було розраховано середнє квадратичне відхилення:

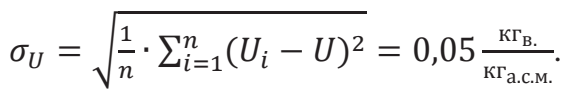

Відповідно коефіцієнт кореляції для значень вологовмісту становить $\rho_{U}=92 \%$.

Із рисунку 4 видно, що одна і та ж кількість пасти діоксиду титану при початковій температурі теплоносія $120{ }^{\circ} \mathrm{C}$

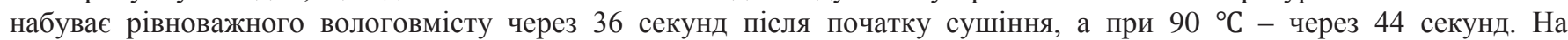
графічних залежностях чітко простежується перший та другий періоди сушіння, а значення $U_{1 \kappa p}=0,3011 \frac{\kappa_{\text {а.с.м. }}}{\kappa_{\text {к }}}$.

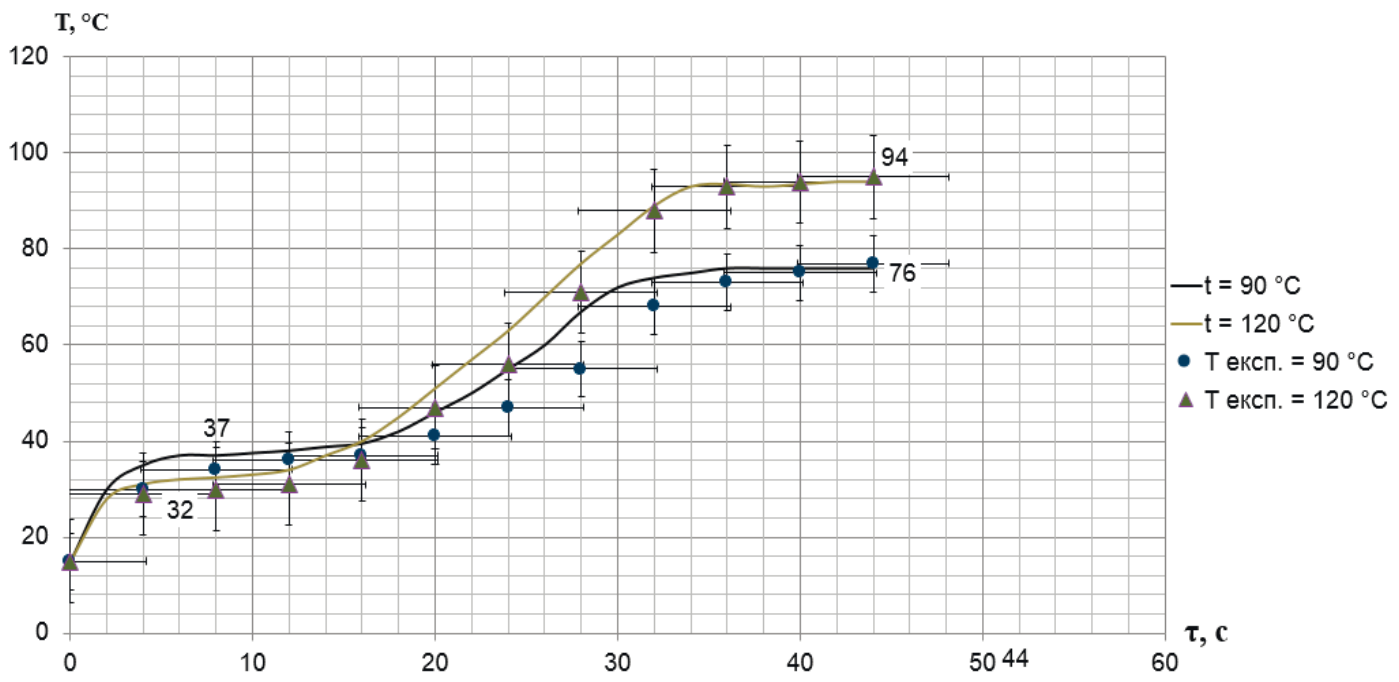

Рис. 5 - Порівняння теоретичних і експериментальних значень температури пасти діоксиду титану від часу сушіння

Середнє квадратичне відхилення теоретичних і експериментальних значень температури продукту становить:

$$
\sigma_{T}=\sqrt{\frac{1}{n} \cdot \sum_{i=1}^{n}\left(T_{i}-T\right)^{2}}=4,13^{\circ} \mathrm{C} .
$$

Відповідно коефіцієнт кореляції для значень вологовмісту становить $\rho_{T}=96 \%$. 
Із рисунку 5 видно що температура мокрого термометра продукту складає $32{ }^{\circ} \mathrm{C}$ i $37^{\circ} \mathrm{C}$ при початковій температурі теплоносія $90{ }^{\circ} \mathrm{C}$ i $120^{\circ} \mathrm{C}$ відповідно. Із графіків простежується ділянка постійної температури (температури мокрого термометра продукту), що відповідає ділянці першого періоду сушіння, коли швидкість сушіння є сталою.

Аналіз отриманих результатів процесів сушіння та досушування тонкодисперсних частинок $\mathrm{TiO}_{2}$ у вихровому потоці теплоносія показує, що видалення адсорбційної вологи обмежує ефективність процесу сушіння. Для інтенсифікації сушіння і збільшення залишкової сухості кінцевого продукту необхідно збільшувати величину густини теплового потоку теплоносія та поверхню контакту агломератів пасти діоксиду титану із теплоносієм, шляхом багаторазового і безперервного подрібнення агломератів продукту.

\section{Висновки}

Встановлено кінетичні параметри процесів сушіння і досушування тонкодисперсної пасти діоксиду титану в оригінальному вихровому сушильному апараті, достовірність значень яких підтверджена експериментальними дослідженнями. Результати дослідження тепломасообміну процесу сушіння засвідчують, що:

- фізична модель процесів сушіння та досушування тонкодисперсної пасти діоксиду титану обгрунтована вірно і описує дійсні процеси, які відбуваються в сушильній камері оригінального апарату;

- рішення математичної моделі процесів сушіння $\mathrm{i}$ досушування пасти $\mathrm{TiO}_{2}$ дозволило отримати: значення вологовмісту і температури продукту, що залежать від часу сушіння, час сушіння продукту, швидкість сушіння та коефіцієнт сушіння;

математична модель перевірена на адекватність, шляхом проведення експериментальних досліджень процесів сушіння і досушування пасти діоксиду титану із використання оригінального сушильного апарату вихрового типу. Коефіцієнти кореляції експериментальних і теоретичних значень становлять $\rho_{U}=92 \%$ і $\rho_{T}=96 \%$ відповідно;

отримані результати дозволять скласти алгоритм розрахунку промислового сушильного апарату, енергозатрати на проведення процесів сушіння будуть у 2,5 рази менші, порівняно із аналогами.

\section{Список використаних джерел}

[1] Бурдо О. Г., Безбах И. В., Зыков А. В. Повышение энергетической эффективности процессов обезвоживания пищевого сырья. Энергетика теплотехнологии и энергосбережение. 2008. № 2. С. 23-28.

[2] Попов А. М., Доня Д. В., Кравченко С. Н., Плотникова И. О., Плотников К. Б., Хлопотов И. В. Изменение фазовых характеристик влажных дисперсных систем. Фундаментальные исследования. 2016. № 11. С. 318 322.

[3] Пахомов А. Н., Пахомова Ю. В. Типы кинетических кривых, получаемых при сушке капель жидких дисперсных продуктов. Химическая технология. 2014. № 10. С. 620-623.

[4] Марчевський В. М., Гробовенко Я. В. Процес сушіння наповнювача паперового полотна. Вісник Національного технічного університету України «КПІ», Хімічна інженерія екологія та ресурсозбереження. 2013. № 1. С. 43-45.

[5] Марчевський В. М., Гробовенко Я. В. Процес сушіння діоксиду титану. Міжнародний науковий журнал. 2016. № 5. С. 22-25.

[6] Алексанян И. Ю., Титова Л. М., Нугманов А. Х. Моделирование процесса сушки дисперсного материала в кипящем слое. Техника и технология пищевых производств. 2014. № 3. С. 96-100.

[7] Дмитриев В. М., Сергеева Е. А. Конвективная сушка полидисперсных материалов в аппаратах закрученного взвешенного слоя. Вестник Тамбовского государственного технического университета. 2013. № 3. С. $602-606$.

[8] Журавлев А. В., Казарцев Д. А., Бородкина А. В. Комбинированные аппараты с закрученным потоком теплоносителя для сушки дисперсных материалов. Технологии пищевой и перерабатывающей промышленности АПК - продукты здорового питания. 2014. № 2. С. 52-59.

[9] Khanali M., Rafiee S. Investigation of hydrodynamics, kinetics, energetic and exergetic aspects of fluidized bed drying of rough rice. International journal of food engineering. 2014. Vol. 10. No. 1. P. 39-50.

[10] Aghbashlo M. Measurement techniques to monitor and control fluidization quality in fluidized bed dryers. Drying Technology. 2014. Vol. 32. No. 9. P. 1005-1051.

\section{References}

[1] O. G. Burdo, I. V. Bezbah, and A. V. Zykov, "Povyshenie jenergeticheskoj jeffektivnosti processov obezvozhivanija pishhevogo syr'ja", Jenergetika teplotehnologii i jenergosberezhenie, no. 2, pp. 23-28, 2008.

[2] A. M. Popov, D. V. Donja, S. N. Kravchenko, I. O. Plotnikova, K. B. Plotnikov, I. V. Hlopotov, "Izmenenie fazovyh harakteristik vlazhnyh dispersnyh sistem”, Fundamental'nye issledovanija, no. 11, pp. 318-322, 2016.

[3] A. N. Pahomov, J. V. Pahomova, “Tipy kineticheskih krivyh, poluchaemyh pri sushke kapel' zhidkih dispersnyh produktov”, Himicheskaja tehnologija, no. 10, pp. 620-623, 2014.

[4] V. M. Marchevs'kii, J. V. Grobovenko, "Proces sushinnja napovnjuvacha paperovogo polotna”, Visnik Nacional'nogo tehnichnogo universitetu Ukraïni «KPI», Himichna inzhenerija ekologija ta resursozberezhennja, no. 1, pp. 43-45, 2013. 
[5] V. M. Marchevs'kii, J. V. Grobovenko, "Proces sushinnja dioksidu titanu", Mizhnarodnij naukovij zhurnal, no. 5, pp. $22-25,2016$.

[6] I. J. Aleksanjan, L. M. Titova, A. H. Nugmanov, "Modelirovanie processa sushki dispersnogo materiala v kipjashhem sloe", Tehnika i tehnologija pishhevyh proizvodstv, no. 3, pp. 96-100, 2014.

[7] V. M. Dmitriev, E. A. Sergeeva, "Konvektivnaja sushka polidispersnyh materialov v apparatah zakruchennogo vzveshennogo sloja", Vestnik Tambovskogo gosudarstvennogo tehnicheskogo universiteta, no. 3, pp. 602-606, 2013.

[8] A. V. Zhuravlev, D. A. Kazarcev, A.V. Borodkina, "Kombinirovannye apparaty s zakruchennym potokom teplonositelja dlja sushki dispersnyh materialov", Tehnologii pishhevoj i pererabatyvajushhej promyshlennosti APK produkty zdorovogo pitanija, no. 2, pp. 52-59, 2014.

[9] M. Khanali, S. Rafiee, "Investigation of hydrodynamics, kinetics, energetic and exergetic aspects of fluidized bed drying of rough rice", International journal of food engineering, vol. 10, no. 1, pp. 39-50, 2014.

[10] M. Aghbashlo, "Measurement techniques to monitor and control fluidization quality in fluidized bed dryers", Drying Technology, vol. 32, no. 9, pp. 1005-1051, 2014. 